\title{
A Novel Hotel-based Syndromic Surveillance System for the Caribbean Region
}

\author{
Jonathan Edwin* and Lisa Indar \\ Surveillance, Disease Prevention and Control Division, Caribbean Public Health Agency, Port of Spain, Trinidad and Tobago
}

\section{Objective}

To describe the Caribbean Public Health Agency's (CARPHA) Tourism and Health Information System (THiS), a web-based syndromic surveillance system to increase the capacity of Caribbean countries to monitor the health of visitors and staff in hotels, and detect potential infectious disease outbreaks for early and coordinated public health response.

\section{Introduction}

The tourism industry is highly vulnerable to Health, Safety, and Environmental Sanitation (HSE) threats. The Caribbean is the most tourism dependent region in the world, with over 54.2 million stayover and cruise ship arrivals in 2015, generating revenues of \$US29.6 billion and contributing to $15 \%$ of the Gross Domestic Product (GDP) and 2,255,000 jobs [1]. Tourists and staff are at an increased risk of acquiring infectious diseases, given the mass-gathering of individuals with varying levels of susceptibility and often times in close quarters in hotels and cruise ships. To prevent the spread of infectious diseases in these settings, early warning and response to potential public health threats is essential. To increase the capacity of countries in the Caribbean monitor and protect the health of tourists and staff in their hotel establishments, THiS was designed as an early warning system for infectious disease outbreaks.

\section{Methods}

CARPHA launched the Regional Tourism Health Information, Monitoring and Response System in 2016 with donor funding received from the Inter-American Development Bank (IDB). The overall objective of THMRS project from 2016-2018 is to improve participating country's capacity to provide cost-effective and quality health, food safety and environmental solutions to HSE threats. As part of the THMRS project, the development of a hotel-based syndromic surveillance system for early warning and response to infectious diseases was developed.

THiS was developed in collaboration with six participating IDB countries: Barbados, Bahamas, Belize, Guyana, Jamaica, Trinidad and Tobago. The implementation plan (2016-2018) with each country involved three stages:

1) Project Operations, Coordination, Management (including Advocacy, and Endorsement)

2) Development of the project outputs: gap analysis and best practices; development of surveillance guidelines and training modules, HSE Standards

3) Implementation in participating countries (i.e. technical visits, ongoing technical coordination): Preparation, Buy-in, Training and Launch

The web-based design of THiS enables the collection of realtime data which will inform health service delivery decisions/ policies, strengthen national and regional health monitoring efforts, and trigger a rapid coordinated response to outbreaks, and prevent escalation of tourism HSE incidents. The system involves a webbased questionnaire with a series of 11 short questions that ask the user for basic non-identifiable demographic information as well as symptoms. The reported symptoms are used by the system to generate six syndromes: Gastroenteritis, Undifferentiated Fever, Hemorrhagic
Fever, Fever with Neurologic symptoms. Fever with Respiratory symptoms, Fever with Rash.

Data entry persons include hotel staff, physicians, and the case. Access to anlaytic dashboards of the aggregated data is limited to registered hotel staff (i.e. Managers), the Ministry of Health of the country where the hotel reporting is located, and CARPHA.

The limited level of baseline data for syndromes in the Caribbean region means that statistical aberration detection mechanisms for most syndromes will not be available until THiS collects at least one year's worth of data. However, for acute gastroenteritis, until a more accurate threshold can be generated, a cut-off of 3\% ill (staff and guests) will be used for alerting potential outbreaks. This is scheduled to be live and functional beginning in hotel facilities in Trinidad and Tobago at the beginning of October 2016.

By the end of 2016, THiS will be operating in facilities in all six participating countries, allowing for the collection of baseline data for syndromes occurring among tourists and staff in hotel-settings, and providing a mechanism to detect and response to emerging public health threats early and efficiently.

\section{Conclusions}

Establishing this system is critical to improving countries' capacities to support the overall health surveillance system of the tourism-dependent Caribbean economies, enabling countries to collect real-time data which will inform health service delivery decisions/policies, strengthen national and regional health monitoring efforts to trigger a rapid coordinated response to outbreaks and other crises and thus prevent tourism HSE incidents.

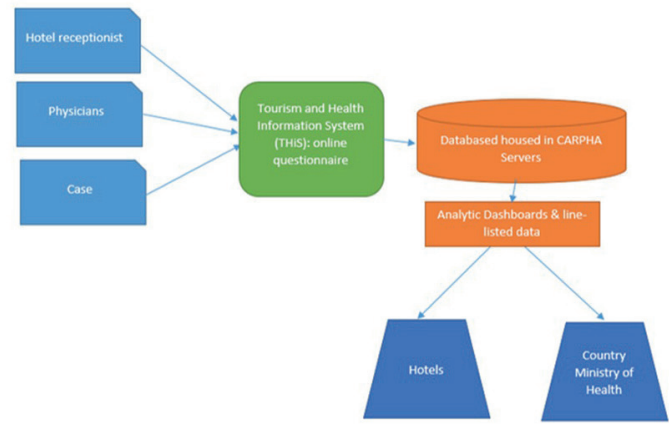

Figure. Data flow schematic for web-based Tourism \& Health Information System (THis) 
ISDS 2016 Conference Abstracts

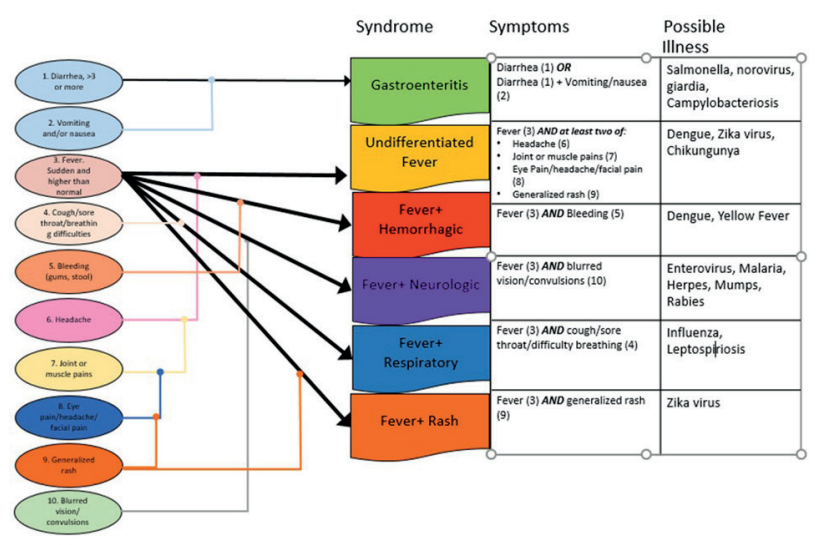

\section{Keywords}

Syndromic surveillance; hotel-based surveillance; Caribbean surveillance; infectious diseases

\section{Acknowledgments}

This Project would not be possible without the donor funding provided by the Inter-American Development Bank (IDB), and collaboration from the Caribbean Tourism Organization and participating jurisdictions: Barbados, Bahamas, Belize, Guyana, Jamaica, Trinidad and Tobago

\section{References}

1. Travel and Tourism Economic Impact 2016: Caribbean. London, United Kingdom: World Travel and Tourism Council (WTTC); 2016 [September 9 2016]. Available from: http://www.wttc.org/-/media/ files/reports/economic-impact-research/regions-2016/caribbean 2016. pdf

\section{*Jonathan Edwin \\ E-mail: indarlis@carpha.org}

